\title{
ELECTRICAL PROPERTIES OF THE PULSED-LASER DEPOSITED SURFACE-BARRIER STRUCTURES BASED ON p-Si
}

\author{
K. AVJYAN \\ Semiconductor physics department, Institute of Radiophysics and Electronics of NAS of Armenia \\ Alikhanyan brothers 1, Ashtarak, 0203, Armenia \\ avjyan@yahoo.com

\section{A. KHACHATRYAN} \\ Semiconductor physics department, Institute of Radiophysics and Electronics of NAS of Armenia \\ L. MATEVOSYAN \\ Semiconductor physics department, Institute of Radiophysics and Electronics of NAS of Armenia \\ G. VARDANYAN \\ Semiconductor physics department, Institute of Radiophysics and Electronics of NAS of Armenia

\section{ZH. PANOSYAN} \\ “Heliotechnics" Laboratory of State Engineering University of Armenia, Yerevan \\ YE. YENGIBARYAN \\ “Heliotechnics" Laboratory of State Engineering University of Armenia, Yerevan
}

\begin{abstract}
Surface-barrier structures based on $\mathrm{p}$-Si where fabricated by pulsed-laser deposition method. Electrical properties (current-voltage and capacitance-voltage) of these structures were studied. It is shown, that the forward current $((+)$ on $\mathrm{p}-\mathrm{Si})$ varies as a $\mathrm{J}=\mathrm{J}_{0} \exp (\mathrm{eU} / \mathrm{nkT})$ and surface-barrier structures based on high-resistivity $\mathrm{p}-\mathrm{Si}$ are light-sensitive.
\end{abstract}

Keywords: Pulsed-laser deposition; surface-barrier structure; electrical properties

\section{Introduction}

Surface-barrier structures (SBS) are one of the most promising objects for a create of a high-speed operation and radiation-hard semiconductor devices, which are much used in modern opto- and microelectronics. In particular, they can be used as detectors of x-ray and gamma radiation, neutron detectors and detectors of terahertz frequency range. 
Amorphous carbon films (a-C) and structures based on them have an important practical interest due to the unique physical and chemical properties (chemical durability, high hardness and thermal conductivity, transparency in the visible and infrared wavelengths and biocompatibility). The main elements of semiconductor electronics, such as tunnel diodes ${ }^{1}$, metal insulator semiconductor structure ${ }^{2}$, heterojunction diodes ${ }^{3}$, are implemented on the basis of a-C and silicon (basic material of functional electronics).

The development of electronics also stimulates the researchers to explore the possibilities of obtaining SBS in non-trivial conditions, which include, in particular, strongly non-equilibrium conditions of film growth, achieved within the method of pulsed-laser deposition (PLD) $)^{4.5}$.

This paper presents the results of investigations of the electrical properties of a$\mathrm{C} / \mathrm{p}-\mathrm{Si}$ and $\mathrm{Sb} / \mathrm{p}-\mathrm{Si} \mathrm{SBS}$, obtained by the vacuum PLD. SBS were fabricated at room temperature without chemical or ion etching of $\mathrm{p}$-Si substrate surface and hightemperature annealing unlike other technologies.

\section{Experimental Details}

PLD set up consists of a Q-switched glass: $\mathrm{Nd}^{3+}$ laser $(1.064 \mu \mathrm{m}$ wavelength, $30 \mathrm{~ns}$ pulse duration, laser energy - $3 \mathrm{~J}$ per pulse, intensity of $\sim 10^{9} \mathrm{~W} / \mathrm{cm}^{2}$ in the targets irradiation zone) and a vacuum chamber with residual gas pressure $3 \cdot 10^{-6} \mathrm{~mm} \mathrm{Hg}$. High-resistivity $\left(>10^{4} \mathrm{ohm} \mathrm{cm}\right)$ and low-resistivity $(15 \mathrm{ohm} \mathrm{cm})$ p-type factory quality silicon (thickness $400 \mu \mathrm{m}$ ) wafers were used as a substrate. The selection of silicon wafers (natural oxide is not more than 3-4 nm) carried out on thin-film measurement system Filmetrics F20. Most usable in semiconductor electronics metals In and $\mathrm{Sb}$ have been selected for the fabrication of low-resistance contacts and barrier structures. Silicon based barrier structures have also been obtained by laser deposition of amorphous carbon (a-C) film from the carbon target. Silicon wafers were degreased in pure acetone, washed in redistilled water and dried in air jet. Short-time (20-30 $\mathrm{min})$ annealing of the silicon substrates were made before the deposition of $\mathrm{Sb}(\sim 5 \mathrm{~nm})$ and a-C $(\sim 70 \mathrm{~nm})$ layers at the temperature of $100^{\circ} \mathrm{C}$ and under vacuum of $3 \cdot 10^{-6} \mathrm{~mm} \mathrm{Hg}$. SBS based on silicon were fabricated by PLD method at room temperature without chemical or ion etching of $\mathrm{p}-\mathrm{Si}$ substrate surface and high-temperature annealing. Low-resistance contacts to the obtained SBS were fabricated by laser deposition of In in a same technological cycle and were metalized by physical vapor deposition of In. Low-resistance contacts fabricated under this conditions are linear and stable in a wide range of temperature (77-300 K). One of the $\mathrm{Sb} / \mathrm{p}-\mathrm{Si}$ samples was covered with a protective a-C layer $(\sim 70 \mathrm{~nm})$ from the side of $\mathrm{Sb}$ by PLD method after deposition of low-resistance contacts to $\mathrm{Sb} / \mathrm{p}-\mathrm{Si}$ ( $\mathrm{Sb} / \mathrm{p}-\mathrm{Si}$ covered aC). Current density-voltage (J-U) and capacitance-voltage (C-U) characteristics of fabricated SBS carried out at room temperature. J-U characteristics of fabricated SBS were investigated under white light illumination also. 


\section{Results and discussion}

Measured at room temperature dark J-U characteristics of fabricated SBS Sb/p-Si and a$\mathrm{C} / \mathrm{p}-\mathrm{Si}$ on low-resistivity $\mathrm{p}-\mathrm{Si}$ are shown in Fig. 1. We have a rectifying junctions at all fabricated samples unexceptionally. As in the model of metal-semiconductor «Shcottky» barrier, the forward current $((+)$ on $\mathrm{p}-\mathrm{Si})$ is due to majority carrier flow across a barrier in all obtained junctions, and it varies as a $\mathrm{J}=\mathrm{J}_{0} \exp (\mathrm{eU} / \mathrm{nkT})\left(\mathrm{J}_{0}-\right.$ saturation current, $\mathrm{n}-$ nonideality coefficient) in a range of applied bias $0.08-0.45 \mathrm{~V}$ for SBS Sb/p-Si, and in a range of applied bias $0.25-1.2 \mathrm{~V}$ for $\mathrm{SBS}$ a-C/p-Si. The barrier heights of fabricated structures were calculated from $\mathrm{J}_{0}=\mathrm{A}^{* *} \mathrm{~T}^{2} \exp \left(-\mathrm{e} \Phi_{\mathrm{b}}{ }^{\mathrm{I}} / \mathrm{kT}\right)(\mathrm{A} * *=35 ; \mathrm{T}=300 \mathrm{~K})$.

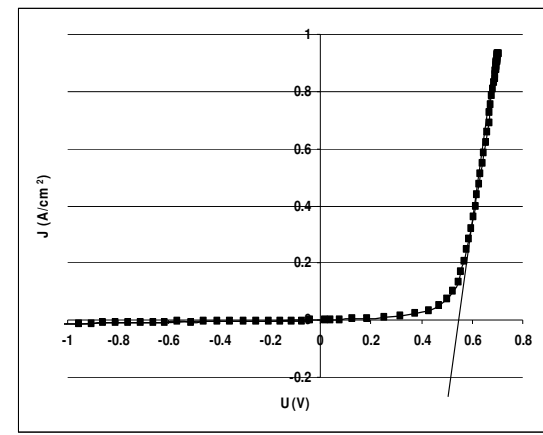

a)

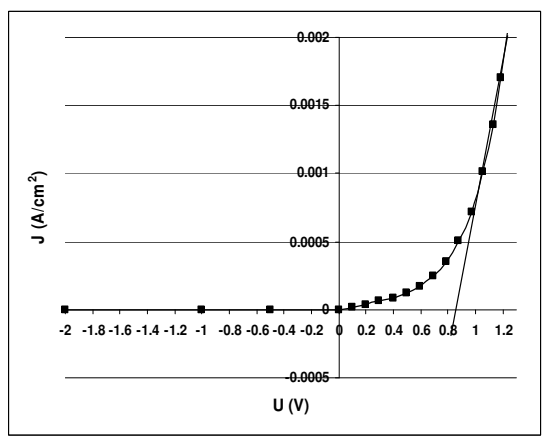

b)

Fig. 1 Dark J-U characteristics of SBS a) Sb/p-Si and b) a-C/p-Si.

Fig. 2 shows $1 / \mathrm{C}^{\mathrm{n}}$ dependences on the voltage applied to the SBS Sb/p-Si and a$\mathrm{C} / \mathrm{p}-\mathrm{Si}$ measured at $1 \mathrm{MHz}$. The linearization of dependence $\mathrm{C}^{-2}-\mathrm{U}$ indicates the sharpness of impurity distribution in the space charge region. The table 1 shows the main parameters of obtained SBS.

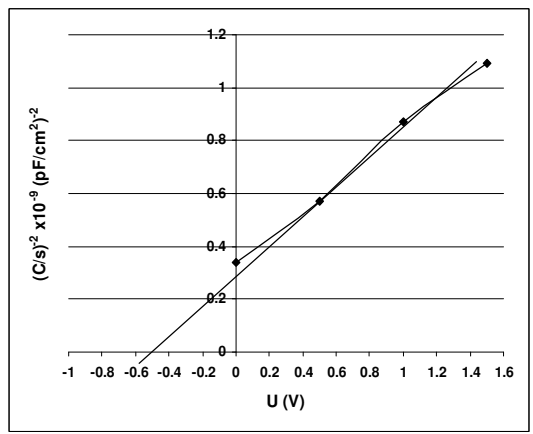

a)

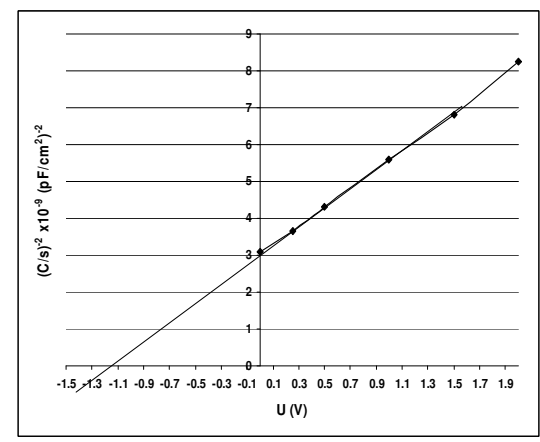

b)

Fig. 2 C-U characteristics of SBS a) Sb/p-Si and b) a-C/p-Si. 
Table 1. The main parameters of SBS fabricated on low-resistivity p-Si.

\begin{tabular}{llll}
\hline Type of structure & $\begin{array}{l}\text { ratio of forward current to } \\
\text { reverse at } 0.65 \mathrm{~V}\end{array}$ & $\mathrm{n}$ & $\Phi_{\mathrm{b}}^{\mathrm{I}}, \mathrm{eV}$ \\
\hline $\mathrm{Sb} / \mathrm{p}-\mathrm{Si}$ & 80 & 5.5 & 0.55 \\
$\mathrm{a}-\mathrm{C} / \mathrm{p}-\mathrm{Si}$ & 120 & 11 & 0.7 \\
\hline
\end{tabular}

$\mathrm{J}-\mathrm{U}$ characteristics of SBS fabricated on low-resistivity p-Si were investigated under natural daylight $\left(20-30 \mathrm{~mW} / \mathrm{cm}^{2}\right)$ on conditions close to AM1.5. We found that all of fabricated structures are not light-sensitive. As in the case of low-resistivity substrates, measured at room temperature dark I-U characteristics shows, that SBS fabricated on high-resistivity $\mathrm{p}$-Si are a rectifying junctions unexceptionally and the forward current $((+)$ on $\mathrm{p}-\mathrm{Si})$ varies as a $\mathrm{J}=\mathrm{J}_{0} \exp (\mathrm{eU} / \mathrm{nkT})$ in a range of applied bias $0.1-0.5 \mathrm{~V}$. The barrier heights of fabricated SBS were calculated from $\mathrm{J}_{0}=\mathrm{A} * * \mathrm{~T}^{2} \exp \left(-\mathrm{e} \Phi_{\mathrm{b}}{ }^{\mathrm{I}} / \mathrm{kT}\right)$. The table 2 shows the main parameters of SBS obtained on high-resistivity $\mathrm{p}-\mathrm{Si}$.

Table 2. The main parameters of SBS fabricated on high-resistivity p-Si.

\begin{tabular}{llll}
\hline Type of structure & $\begin{array}{l}\text { ratio of forward current to } \\
\text { reverse at } 0.5 \mathrm{~V}\end{array}$ & $\mathrm{n}$ & $\Phi_{\mathrm{b}}{ }^{\mathrm{I}}, \mathrm{eV}$ \\
\hline $\mathrm{a}-\mathrm{C} / \mathrm{p}-\mathrm{Si}$ & 150 & 4 & 0.62 \\
$\mathrm{Sb} / \mathrm{p}-\mathrm{Si}$ & 50 & 5.5 & 0.63 \\
$\mathrm{Sb} / \mathrm{p}-\mathrm{Si}$ covered a-C & 280 & 3 & 0.6 \\
\hline
\end{tabular}

J-U characteristics of fabricated structures were investigated under natural daylight like SBS on low-resistivity $\mathrm{p}-\mathrm{Si}$. We found that all of fabricated structures are light-sensitive. Covered with a-C layer by the PLD method Sb/p-Si sample is more light sensitive than $\mathrm{Sb} / \mathrm{p}-\mathrm{Si}$ barrier structure. Short-circuit current density $\mathrm{J}_{\mathrm{sc}}=1 \mathrm{~mA} / \mathrm{cm}^{2}$ and open-circuit voltage $\mathrm{U}_{\mathrm{oc}}=0.2 \mathrm{~V}$ for $\mathrm{Sb} / \mathrm{p}$-Si and correspondingly $6 \mathrm{~mA} / \mathrm{cm}^{2}$ and $0.26 \mathrm{~V}$ for $\mathrm{Sb} / \mathrm{p}-\mathrm{Si}$ structures covered with a-C layer were obtained. We are assume, that the surface recombination decreases after deposition of a-C layer on the $\mathrm{Sb} / \mathrm{p}-\mathrm{Si}$ barrier structure.

\section{Conclusion}

SBS based on p-Si were fabricated at room temperature by PLD method in a unified technological cycle without chemical or ion etching of p-Si substrate surface and hightemperature annealing. We found, that all of SBS fabricated on p-Si are a rectifying junctions unexceptionally and the forward current $((+)$ on $\mathrm{p}-\mathrm{Si})$ varies as a $\mathrm{J}=\mathrm{J}_{0} \exp (\mathrm{eU} / \mathrm{nkT})$. Also we found, that SBS fabricated on high-resistivity p-Si are lightsensitive. Covered with a-C layer by the PLD method Sb/p-Si sample is more light sensitive than $\mathrm{Sb} / \mathrm{p}$-Si barrier structure. We are assume, that the surface recombination 
decreases after deposition of a-C layer on the $\mathrm{Sb} / \mathrm{p}-\mathrm{Si}$ barrier structure. The obtained results can be used in the silicon based electronics.

\section{Acknowledgments}

Part of this work was supported by the program of International Innovation Centre for Nanotechnology C.I.S. \#10882.

\section{References}

1. S. Bhattacharyya, S. Silva, Appl. Phys. Lett. 90, 082105 (2007).

2. N. Konofaos, C. B. Thomas, J. Appl. Phys. 81, 9 (1997).

3. V. S. Veerasmy, G. A. J. Amartunga, J. S. Park, H. S. Mackenzie, W. I. Milne, IEEE Trans. on Electron Devices 42, 577 (1995).

4. Yu.A. Bityurin, S.V. Gaponov et al, Sov. Electronnaja Promishlennost 5-6, 110 (1981)

5. J.C. Miller, Laser Ablation - Principles and Applications, (Springer-Verlag, Berlin, 1994) 